\title{
An investigation into the aesthetic ratings of fortified foods commonly provided in hospitals
}

\author{
S. Memmott, J. Jones, H. I. M. Davidson and E. Bannerman \\ Queen Margaret University, Queen Margaret University Drive, Musselburgh, East Lothian, EH21 6UU
}

It is now well recognised that the hospital food service has a central role to play in the management of malnutrition within the clinical setting $^{(1)}$. Provision of an energy and nutrient dense diet for nutritionally vulnerable patients has been recommended ${ }^{(2)}$. Food fortification is a strategy commonly used in hospital catering to achieve energy and nutrient dense food choices. However, the level of fortification that should be aimed for is not clear ${ }^{(3)}$, although the palatability of a food is important to maximise food intakes ${ }^{(4)}$. The aim of this study was to compare the aesthetic ratings of foods commonly provided in hospitals, which had been fortified to different levels.

A within-subjects repeated measures design, evaluating three products (soup, mashed potato, milk-pudding) was carried out. Fortification levels were based on recommended energy and protein values for energy and nutrient-dense diets ${ }^{(2)}$ and also levels that account for published levels of patients' plate-wastage ${ }^{(5)}$. Subjects were either males or females $>18$ years, in good health, no medical or dietary restrictions, no food allergy or intolerance to any of the ingredients used in the test foods. Subjects attended three evaluation sessions separated by one week intervals. At each session subjects were asked to rate four versions of the product for aesthetic attributes using anchored $100 \mathrm{~mm}$ visual analogue scales (appearance, aroma, taste, texture, after-taste and pleasantness). The order in which products were given was randomised for each participant to prevent bias. Data were analysed using two-way ANOVA with post hoc comparisons, with statistical significance $P<0.05$.

Eleven females (19-45 years) rated the four levels of fortification for each food. Higher levels of fortification were found to have a detrimental affect on the aesthetic ratings of soup (texture $F=4.01, P=0.038$ ) and milk-pudding (taste $F=3.71, P=0.034$; texture $F=7.55, P=0.006$; pleasantness $F=4.56, P=0.021$; aftertaste $F=4.47, P=0.015$ ).

Higher levels of energy and protein food fortification can result in a product that is aesthetically unappealing and thus unlikely to be eaten. Further research is needed to identify the optimal level of nutrient fortification in order to maximise patients' food, energy and nutrient intakes. This needs to consider the overall aesthetic properties of the food, what products are used to fortify the food and determination of the effect these have on appetite parameters and subsequent food intakes.

1. NHS Quality Improvement Scotland (2003) Clinical Standards for Food, Fluid and Nutritional Care in Hospitals.

2. Scottish Government Food In Hospitals: National catering and nutrition specification for food and fluid provision in hospitals in Scotland. Edinburgh: Scottish Government; 2008.

3. Scottish Intercollegiate Guideline Network. Management of Patients with Stroke: Identification and Management of Dysphagia. A National Clinical Guideline. 119. NHS QIS, 2010.

4. Blundell JE \& Stubbs RJ (1999) Eur J Clin Nutr 54, 988-96.

5. Wilson A, Evans S \& Frost G (2000) J Hum Nutr Diet 13, 271-275. 